http://jmscr.igmpublication.org/home/ ISSN (e)-2347-176x ISSN (p) 2455-0450

crossref DOI: https://dx.doi.org/10.18535/jmscr/v7i8.03

\title{
Evaluation of Outcome of the Vaccum Assisted Closure in Patients with Infected Wound of Musculoskeletal System
}

\author{
Authors \\ Dr Malik Naseer Ahmad, Dr Rajinder Singh, Dr Bias Dev, Dr Sheikh Khalid \\ Dr Tanveer Ahmad Bhat, Dr Imtiyaz Beigh
}

\begin{abstract}
Introduction: Infections to musculoskeletal system has always been a matter of great worry to the orthopedic surgeon. Wound healing remains a challenging clinical problem to orthopedic surgeon and correct, efficient wound management remains essential in total. To overcome this complication a novel innovation in wound therapy, Negative pressure wound therapy (NPWT), also known as vacuum assisted closure (VAC) dressing, which was described initially by the Fleishmann in 1993. And was introduced in clinical practice by Argenta and Morykwas, became an important and effective tool for successful treatment of infection in complex wounds. Negative pressure wound therapy (NPWT) has been associated with low complication rate and better patient compliance by providing greater comfort as well as reducing time of hospitalization, use of antibiotics, and number of dressing changes.

Aim: The aim of this study was to evaluate the results and benefits brought by the topical application of Vacuum-assisted Closure (VAC) in patients with infected wounds of musculoskeletal system.

Methods: This prospective study was conducted in a tertiary care hospital of north India from January 2017 to December 2018. The VAC therapy was used in 52 patients having infected wound of the musculoskeletal system with male to female ratio of 1.73:1. All these wounds failed to be closed primarily or required partial thickness skin grafting (PTSG) or flap coverage. The results were presented in suitable tabular and descriptive form. The negative pressure therapy (NPWT) was applied to the infected wound after proper Wound wash and debridement, in continuous mode for an average length of treatment of 20.63 days with a negative pressure between 75 to $200 \mathrm{mmHg}$.

Results: Intermittent negative pressure was applied in all patients. The frequency of VAC dressing change was done every 4-5 days .the average number of VAC dressing used were 4.3 .the mean use of negative pressure therapy was 20.63 days. The decrease in wound size attained by VAC therapy ranged from 2.8 to $26.3 \mathrm{~cm} 2$, with an average reduction of $12.13 \mathrm{~cm} 2$. All the patients showed a positive outcome with respect to wound healing and complete eradication of infection.

Conclusion: VAC has been a reliable method of treating a variety of different wounds. The dramatic result of the VAC therapy by increases the rate of granulation tissue formation and by lowering of the bacterial counts to accelerate wound healing thus significant reduction in hospital stay and the readmission with the result the burden to the both hospital and to patient has been remarkable especially in developing country with decreased inpatient capacity. The fear of the pain and discomfort to patient due to regular dressing has made the application of VAC for patient a sigh of relief.
\end{abstract}




\section{Introduction}

Wound healing remains a challenging clinical problemto orthopedic surgeon and correct, efficient wound management remain essential in total $^{[1]}$. The infection to the extremities with loss of soft tissue which result in exposure of implant hardware and sensitive structures such as tendons, nerves, and bone has been one of the most challenging problem for the orthopedic surgeon ${ }^{[2,3]}$.A number of surgical options have been described for this problem in the literature, which includes use of colloids, partial or full thickness skin grafting, rotation flaps and, flap transfers. All these surgical options are availed after serial debridement of devitalized tissue of the injured area to provide healthy tissue bed ${ }^{[4]}$. However, this debridement is accompanied with both physical and psychological trauma due to repeated exposure to anesthetic agents severe pain during dressing changes ${ }^{[5]}$. To overcome this complication a novel innovation in wound therapy, Negative pressure wound therapy (NPWT), also known as vacuum assisted closure (VAC) dressing, which was described initially by the Fleishmann in $1993^{[6]}$. And was introduced in clinical practice by Argenta and Morykwas ${ }^{[7]}$, became an important and effective tool for successful treatment of infection in complex wounds. Negative pressure wound therapy (NPWT) has been associated with low complication rate and better patient compliance by providing greater comfort as well as reducing time of hospitalization, use of antibiotics, and number of dressing changes ${ }^{[8,9,10]}$. Negative pressure wound therapy (NPWT) facilitates the healing by improving the rate of angiogenesis, endothelial proliferation, the integrity of the capillary membrane, capillary blood flow and by decreasing interstitial edema and bacterial burden within the wound ${ }^{[11,12,13]}$

The aim of this study was to evaluate the results and benefits brought by the topical application of Vacuum-assisted Closure (VAC) in patients with infected wounds of musculoskeletal system.

\section{Material and Method}

This prospective study was conducted in a tertiary care hospital of north India from January 2017 to December 2018. The VAC therapy was used in 52 patients having infected wound of the musculoskeletal system. All these wounds failed to be closed primarily or required partial thickness skin grafting (PTSG) or flap coverage.

The above patients were selected by using following inclusion and exclusion criteria:

\section{Inclusion Criteria}

- Age $<18$ and $>80$ yrs.

- All lower limb wounds irrespective of cause and location.

- Wound infection presence confirmed by positive culture reports.

- Negative pressure therapy used for treatment in addition to the wound wash/debridement and I/V antibiotics.

- Negative pressure applied for at least 5 days.

\section{Exclusion Criteria}

- Non complaint patient whom removed the VAC dressing before completing 5 days post application.

\section{Technique}

VAC consists of Sterile polyurethane foam/sponge, suction pump, suction pipe, a reservoir, Sterile open - cell structured sponge which is cut to fit the size of wound adequately and is put inside the wound cavity. This sponge allows equal distribution of the negative pressure and also reduces the chances of high negative pressure, which can lead to tissue damage. An adhesive drape was then applied over the wound area with an additional $2-4 \mathrm{~cm}$ border of healthy skin to provide an intact seal, which creates a vacuum by avoiding any contact with external environment. This adhesive seal is cut at only one place through which the tube is placed and this tube is connected with the vacuum generating and collecting unit on the other side. The dressing was applied after proper wound wash and debridement and Dressings were changed after every 4 to 5 days. At every dressing the presence or absence of 
granulation tissue, erythema, infection, and amount of drainage were noted. Routine bacterial cultures and sensitivity testing were done at every dressing. Antimicrobial protocols were followed depending upon the culture and sensitivity report. The vacuum device was used until granulation tissue formed with little or no oedema or drainage,

\section{Results}

A total of 52 patients were included in the study who met the inclusion criteria, with a female to male ration of 1.73:1(table no. 1)

Table No. 1

\begin{tabular}{|l|c|}
\hline MALE & FEMALE \\
\hline 33 & 19 \\
\hline
\end{tabular}

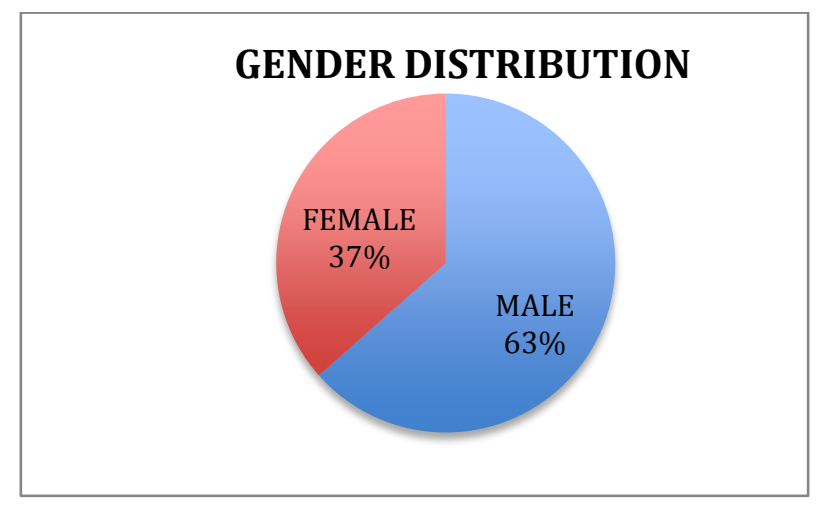

The average patient age was 33.5 years (range 18 to 63 years) (table no. 2)

Table No. 2

\begin{tabular}{|l|l|}
\hline AGE IN YRS & NO. \\
\hline $18-23$ & 08 \\
\hline $30-35$ & 12 \\
\hline $36-40$ & 03 \\
\hline $41-45$ & 07 \\
\hline $46-50$ & 08 \\
\hline $51-55$ & 01 \\
\hline AVERAGE $=$ 33.5yrs \\
\hline
\end{tabular}

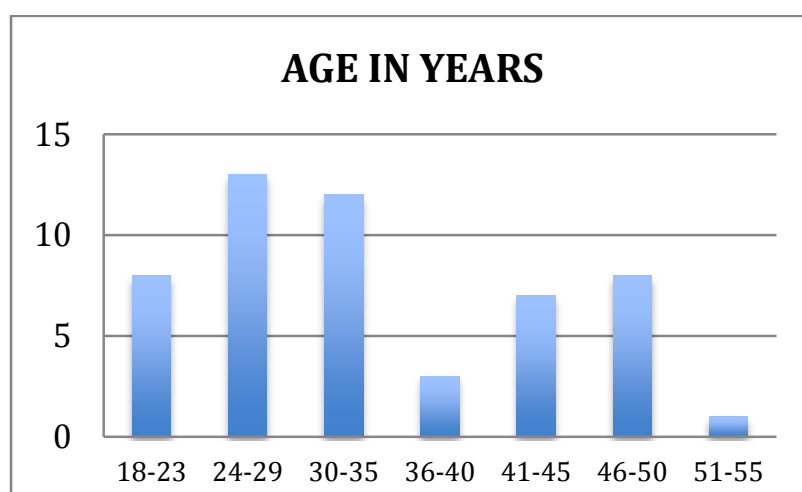

The most common cause of the infected musculoskeletal wound was diabetic ulcers (\%) which was followed by Road traffic accident(\%) and pressure ulcers (\%) due to paraplegia.

Lower limb, 34 (65.38\%) were the commonly affected area followed by trunk $11(21.15 \%)$ and upper extremity 7 (13.46\%) (table no 3 ).

Table No. 3

\begin{tabular}{|l|c|c|}
\hline Sr.no & Wound site & NO of patient \\
\hline 1 & Upper extremity & $\mathbf{0 7}$ \\
& $\bullet \quad$ Shoulder & $\mathbf{0 2}$ \\
& $\bullet$ Arm & $\mathbf{0 0}$ \\
& $\bullet$ Elbow & $\mathbf{0 1}$ \\
& $\bullet$ Forearm & $\mathbf{0 1}$ \\
& $\bullet$ Hand & $\mathbf{0 3}$ \\
\hline 2 & Lower extremity & $\mathbf{3 4}$ \\
& $\bullet$ Thigh & $\mathbf{1 7}$ \\
& $\bullet \quad$ Leg & $\mathbf{0 7}$ \\
& $\bullet$ Ankle & $\mathbf{0 6}$ \\
\hline 3 & - Foot & $\mathbf{1 1}$ \\
\hline
\end{tabular}

The mean duration of the therapy was 20.63 days (range of 14-45 days) (table no 4).

\section{Table No.4}

\begin{tabular}{|l|c|}
\hline $\begin{array}{l}\text { Length Of Treatment } \\
\text { days) }\end{array}$ & NO. OF PATIENT \\
\hline $14-19$ & 31 \\
\hline $20-25$ & 12 \\
\hline $26-30$ & 4 \\
\hline $31-35$ & 2 \\
\hline $36-40$ & 3 \\
\hline $41-45$ & 1 \\
\hline AVERAGE LENGTH \\
OF TREATMENT
\end{tabular}

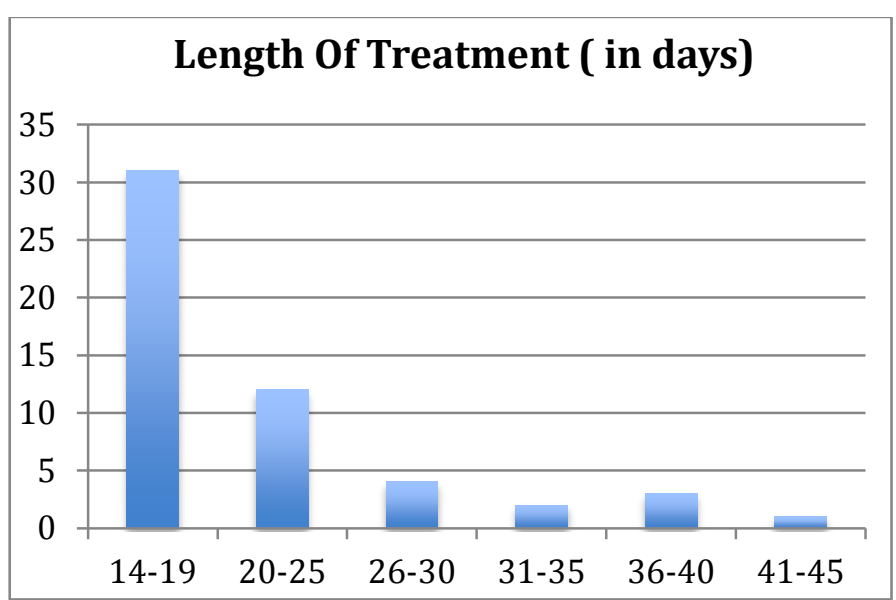

Intermittent negative pressure was applied in all patients. The frequency of VAC dressing change was done every 4-5 days (table no 5). 
Table No. 5

\begin{tabular}{|l|c|}
\hline No. Of VAC Dressing Used & No Of Patients \\
\hline $03-04$ & 37 \\
\hline $50-06$ & 09 \\
\hline $07-08$ & 02 \\
\hline 09-10 & 03 \\
\hline AVERAGE VAC DESSING & $\mathbf{4 . 3}$ \\
\hline
\end{tabular}

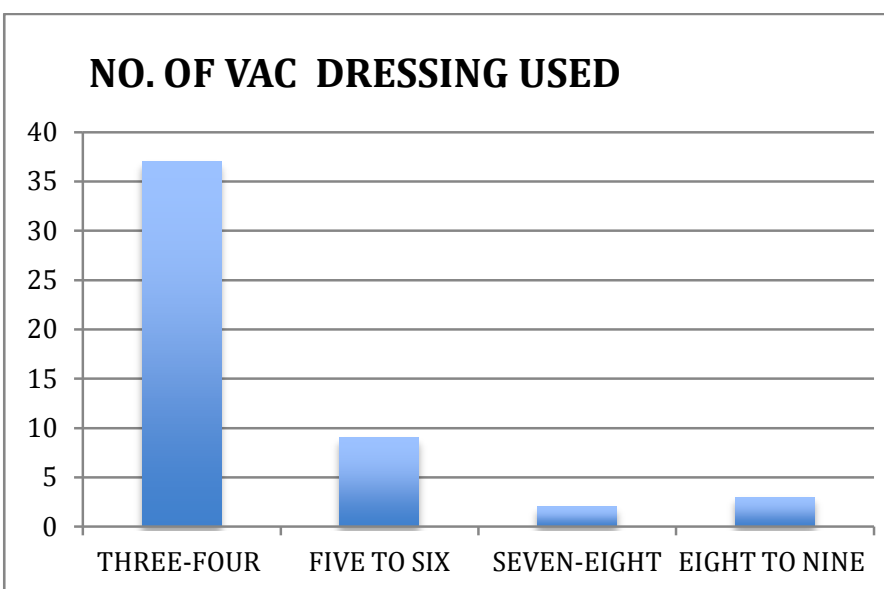

The size of wound area at the time of initial presentation ranged from 6.32 to $108.67 \mathrm{~cm} 2$, with the average area being $43.72 \mathrm{~cm} 2$.

After the completion of VAC therapy, the wound area ranged from 4.13 to $91.46 \mathrm{~cm} 2$, the average area being $29.42 \mathrm{~cm} 2$.

There was decrease in wound size attained by VAC therapy ranged from 2.8 to $26.3 \mathrm{~cm} 2$, with an average reduction of $12.13 \mathrm{~cm} 2$.

Bacterial culture was taken from the wound at time of the initial debridement and before applying the VAC therapy. Repeat culture from the wound bed was taken at the end of the VAC therapy and sent to the microbiology laboratory. All patients achieved positive outcome with respect to wound healing, complete eradication of infection.

Among the 52 patient partial thickness skin grafting (PTSG) was done in 35 patients (67.31\%), 9 patients required flaps to cover the wound and in 8 patients, the wound required no further intervention and healing was uneventful.

\section{Discussion}

The use of VAC therapy was an accepted as an excellent modality of management of wounds that are to be covered with skin grafts. VAC ideally prepares the wound bed by decreasing wound edema and reducing the size of the wound ${ }^{[14]}$, thus facilitates the mobilization of the skin edges for delayed primary closure and in wounds that would require a local rotational or free flap. DeFranzo et $\mathrm{al}^{[15]}$ were able to successfully close 75 lower extremity wounds, 82 percent of which were traumatic or post-orthopedic procedure wounds, 95 percent of the wounds healed primarily; four required the additional removal of hardware or infected sequestrum before finally healing. our study showed promising results of the VAC therapy in consistent to the various other studies regarding final outcome of wound condition, Wounds in our study had an average surface area of $43.72 \mathrm{~cm}^{2}$. This was approximately about 2 times larger than the average wound area of 20.7 $\mathrm{cm}^{2}$ in the study by Armstrong and Lavery ${ }^{[16]}$ the reduction in wound size after VAC therapy was $27.74 \%$ which was in consistent to the study by McCallon et al., with an average decrease in wound surface area of $28.4 \%$ (SD 24.3) after VAC therapy ${ }^{[17]}$. In our study, the length of time taken to complete VAC therapy ranged from 14 to 45 days, with an average of 20.63 days. This was shorter than the average time taken by Armstrong et al of 32.9 days $^{[18]}$ and Clare et al of 57.4 days ${ }^{[19]}$. In the study by Fleishman et $\mathrm{al}^{[20]}$ average number of VAC dressing change were 2.8 per wound which was comparable to our study with 4.3 average dressing change .In our study, wound culture was found to be positive for microorganisms for all patients at the start of VAC therapy. however, at the end of VAC therapy All wounds showed clearance of bacterial infection with repeat culture smillar results were obtained in study of Morykwas et $\mathrm{al}^{[21]}$, with significant reduction in bacterial load of chronic wounds in animal model by the fifth day $(n=5)$, Compared to 11 days in control wounds which were untreated $(n=5)$.In developing country like India the affordibilty of the VAC therapy 


\section{References}

1. Velnar T, Bailey T, Smrkolj V. The Wound Healing Process: an Overview of the Cellular and Molecular Mechanisms. The Journal of International Medical Research. 2009;37(5):1528-1542.

2. Bihariesingh V.J., Stolarczyk E.M., Karim R.B., van Kooten E.O. Plastic solutions for orthopaedic problems. Arch Orthop Trauma Surg. 2004;124(2):73-76.

3. Kramhøft M., Bødtker S., Carlsen A. Outcome of infected total knee arthroplasty. J Arthroplasty. 1994;9(6):617-621.

4. Clifford R.P. Artmed; Porto Alegre: 2002. Fraturasexpostas. Princípios AO do tratamento de fraturas; pp. 617-640

5. McCallon S.K., Knight C.A., Valiulus J.P., Cunningham M.W., McCulloch J.M., Farinas L.P. Vacuum-assisted closure versus saline-moistened gauze in the healing of postoperative diabetic foot wounds. Ostomy Wound Manag. 2000;46(8):28-32.

6. Fleischmann W, Strecker W, Bombelli M, Kinzl L. Vacuum sealing as treatment of soft tissue damage in open fractures. Unfallchirurg. 1993;96(9):488-492.

7. Morykwas MJ, Argenta LC, SheltonBrown EI, McGuirt W. Vacuum-assisted closure: a new method for wound control and treatment: animal studies and basic foundation. Ann Plast Surg. 1997;38(6):553-562

8. Hunter J.E., Teot L., Horch R., Banwell P.E. Evidence-based medicine: vacuumassisted closure in wound care management. Int Wound J. 2007;4(3):256269.

9. Vikatmaa P., Juutilainen V., Kuukasjärvi P., Malmivaara A. Negative pressure wound therapy: a systematic review of effectiveness and safety. Eur J Vasc Endovasc Surg. 2008;36(4):438-448.

10. Scherer S.S., Pietramaggiori G., Mathews J.C., Prsa M.J., Huang S., Orgill D.P. The mechanism of action of the vacuumassisted closure device. PlastReconstr Surg. 2008;122(3):786-797.

11. Chen SZ, Li J, Li XY, Xu LS. Effects of vacuum-assisted closure on wound mic

12. Genecov DG, Schneider AM, Morykwas MJ, Parker D, White WL, Argenta LC. A controlled sub atmospheric pressure dressing increases the rate of skin graft donor site reepithelialisation. Ann Plast Surg. 1998;40:219-25.

13. Weed T, Ratliff C, Drake DB. Quantifying bacterial bio burden during negative pressure wound therapy: does the wound VAC enhance bacterial clearance? Ann Plast Surg. 2004;52:279-80.

14. Mullner T, Mrkonjic L, Kwasny O, et al. The use of negative pressure to promote the healing of tissue defects: a clinical trial using the vacuum sealing technique. $\mathrm{Br} \mathrm{J}$ PlastSurg 1997; 50: 194-9

15. DeFranzo AJ, Argenta LC, Marks MW, et al. The use of vacuum-assisted closure therapy for the treatment of lowerextremity wounds with exposed bone. PlastReconstrSurg 2001 Oct; 108 (5): 1184-91

16. Armstrong DG, Lavery LA. Negative pressure wound therapy after partial diabetic foot amputation: a multicentre, randomised controlled trial. Lancet 2005;366:1704-10.

17. McCallon SK, Knight CA, Valiulus JP, Cunningham MW, McCulloch JM, Farinas LP. Vacuum-assisted closure versus saline-moistened gauze in the healing of postoperative diabetic foot 
wounds.Ostomy/Wound Management. 2000;46(8): 28-34.

18. Armstrong DG, Lavery LA, Abu-Rumman P, Espensen EH, Vazquez JR, Nixon BP, et al. Outcomes of subatmospheric pressure dressing therapy on wounds of the diabetic foot. Ostomy Wound Manage 2002;48:64-8.

19. Clare MP, Fitzgibbons TC, McMullen ST, Stice RC, Hayes DF, Henkel L. Experience with the vacuum assisted closure negative pressure technique in the treatment of non-healing diabetic and dysvascular wounds. Foot Ankle Int 2002;23:896-901.

20. Fleischmann W, Lang E, Klinzl L. Vacuum assisted wound closure after dermatofasciotomy of the lower extremity [in German]. Unfallchirurg 1996; 99 (4): 283-7

21. Morykwas MJ, Argenta LC, SheltonBrown EI, McGuirt W. Vacuum- assisted closure: a new method for wound control and treatment: animal studies and basic foundation. Ann PlastSurg 1997;38:55362. 